\title{
Forming Strong Guest Loyalty: Sustainable Development of Hotel Industry on the Example of Small-Hotels
}

\author{
Dana Naimanbayeva \\ University of International Business, Kazakhstan \\ dnmbva.n@gmail.com
}

\begin{abstract}
The study of customer loyalty is an important part of the activity of any enterprise, which allows achieving significant economic indicators. In modern economic conditions of development of the sphere of tourism and hospitality, consumer behavior is increasingly being evaluated as an indicator of competitiveness of the hotel. For effective development of mini hotels, the number of which is gradually growing, it is important to study the needs and wishes of potential customers. The formation of customer loyalty of hotel services is a difficult task, hotel managers have to analyze not only the needs of consumers, but also the behavior in the market of other hotel enterprises, as well as use the mechanisms of «individualization» of service. The object of the research in the article is consumer behavior in general, and loyalty of guests in particular. The subject of the study is the influence of guest loyalty on the development of mini-hotels. The theoretical side of the article is to study the preferences of hotel customers and identify groups of factors that influence the formation of customer loyalty of hotel services, as well as the needs of customers when visiting certain hotel enterprises. The article analyzes the theoretical and practical aspects of the formation of motivation of potential and real customers of mini-hotels, focuses on the role of marketing management of mini hotels. Based on the conducted survey, groups of consumer preferences of mini-hotel clients were identified. The finding results from the article helped to identify the main motivation of potential customers to make the choice in favor of particular hotel. Customer preferences when choosing a mini-hotel include such variables as: favorable living conditions, comfortable psychological climate, level of service. The empirical main conditions of the article are to generalize the main factors of sustainable development of mini-hotels as one of the forms of development of the hotel industry and increase the tourist attractiveness of the region.
\end{abstract}


Keywords: consumer behavior, guest loyalty, small local hotels, mini-hotels, hotel service, forming guest loyalty as a part of marketing strategy. 


\section{Introduction}

In the current socio-economic conditions of the development of the hospitality industry, more and more attention is attracted to the development of small forms of accommodation, which is also reflected in the Kazakh legal regulation of this sphere. In 2010, Kazakhstan introduced the national standard ST RK EN ISO 18513 - 2010 «Services of small accommodation facilities. General requirements». This is the first regulatory document, establishing general requirements for accommodation facilities with a number of rooms of not more than 50 rooms. The following definitions are given in the standard: «Small accommodation facility - premises used by organizations of various organizational and legal forms, individual entrepreneurs and individuals, equipped to provide temporary accommodation services with a maximum of 50 rooms. Small hotel, small hotel - a small accommodation facility with the number of rooms from sixteen to fifty rooms. Mini-hotel - a small accommodation facility with a numbering background - house from five to fifteen rooms» (Law of the Republic of Kazakhstan on Tourist Services, p. 1).

Although before the adoption of this standard the concept of «mini hotel» was widely used in the media and in the statements of professional hoteliers, but officially it did not exist, since it did not appear in any legislative document. But in the «Classification of hotels and other accommodation facilities» for all without exceptions for hotels with less than 50 numbers, the term was normatively fixed "Small hotels», so for a long time «Small» and «mini-hotels» were synonymous concepts, which was reflected in our review of literature on the subject issue and further analysis. A characteristic feature of any small hotel is the ability to create a comfortable atmosphere for the guest, as well as the maximum personification of individual hotel services. Small hotels in the larger degrees allow you to optimize the volume and quality of services provided, while achieving an effective ratio between the number of staff and number of guests (Bitter, 2014).

At the same time, small hotels are faced with the task of promoting their services, which is impossible without studying the consumer behavior of their guests. In the current development of the tourism and hospitality industry the main character with increasingly degree becomes a specific consumer, characterized by the peculiarity of temperament, character, features of the motivational sphere. It is he and his inner circle who decide 
which travel services to buy, where and how to relax. The central figure of the consumer in the modern market required a detailed and in-depth study of the features of his behavior in the dialogue «product - buyer» (Glotova, 2015).

Hotel services are used by diverse consumer groups, with their individual preferences and wishes, different income levels. However, not all guests of the same hotel have the same taste and needs. Guests of the same hotel are completely different people with different motives and goals (Donskova \& Dunec, 2008).

The modern scientific community has recently begun to pay attention to this problem. Having studied the role of customer needs in hotel services, we noted that in order to identify consumer preferences, it is necessary to use modern marketing research. There are also methods for assessing consumer values in hotels, allowing to identify customer preferences in the qualitative and quantitative indicators of the service system. Some techniques used in assessing customer satisfaction can further enhance the competitiveness of hospitality enterprises (Duhovnaja, Kobeleva \& Shpagina, 2016).

So, the object of study in the article advocates consumer behavior in general and guest loyalty in particular, the subject of research is the effect of guest loyalty on the development of mini-hotels.

\section{Literature Review}

As have already mentioned, the category of small accommodation includes hotels with less than fifty rooms. A number of authors highlight the external and internal factors of the development of small forms of hotels. Among macro factors include: economic trends, socio-cultural factors, development overall, deficit of balance payments, and import of services, state regulation (Kovaleva \& Nikol'skaja, 2016).

At the present stage of development of the tourist and hotel industry, interest in small forms of hotels is due to the needs of the main consumers. Small accommodations quickly adapt to the requirements of their customers, create an atmosphere of home comfort. Analyzing the features of small hotels and their role in the development of the tourism and hospitality industry, it can be noted that the main advantages of mini-hotels are 
providing the client with the opportunity to choose accommodation not only taking into account price, but also location, aesthetic preferences. This allows you to control the quality of services and optimize the volume of services provided (Kovaleva \& Nikol'skaja, 2015).

In this context, a methodology for assessing the quality of service, tested on the example of a hotel organization, has been formed. This involves holding marketing research (Kosheleva, 2012). In addition, the necessity of using a mathematical estimation model is substantiated activities of a small hotel, which helps to increase competitiveness (Levykin \& Djevon, 2014). Small accommodation facilities with a view to attract and retain customers apply various loyalty programs. Of no small importance in building customer relationships are internet technologies: hotel business internet representations, internet marketing, internet CRM systems (Levykin \& Djevon, 2015). In many ways, the behavior of consumers when choosing certain hotel services is associated with consumer expectations. These expectations are based on the use of the following key factors: personal needs, past experience in using services or goods, external communications, interpersonal communication, including assessments of loved people and even rumors. Customers make an assessment of the quality of service on an objective and subjective, quantitative and qualitative indicators (Nikol'skaja \& Vahrina, 2015).

You can define consumer motivation as a person's motivation to meet recreational needs, depending on his individual physiological and psychological characteristics, belief systems, values, inclinations, education, etc. The focus and motives of the consumer affect the formation of his behavior as a buyer of services. Following the author, we believe that the hotel product should have its addressee (Chudnovskij, 2011).

Note that the formation of consumer motivation is influenced by increasing customer loyalty. When developing an effective loyalty program, it is necessary to take into account that the privilege should not only be useful, but truly desirable, that is, give unique advantages that are valuable for a certain category of users (Chudnovskij \& Palshkov, 2012).

All of the above allows mini-hotels to take a strong position in the hotel services market. However, the question arises of a more substantive study of consumer behavior and 
motivation customers in general, and the formation of their loyalty in particular as a factor in the development of mini-hotels (Shahovalov, 2007).

\section{Plan and Methods of the Research}

Quantitative method of the research was chosen. It was made in the form of the questionnaire. The title of it is «Revealing consumer preferences of clients of small hotels». The questionnaire was prepared in Google forms and respondents were asked to answer it upon the check out. A survey of 145 respondents was conducted to evaluate consumer preferences and motivation for visiting mini-hotels of Almaty.

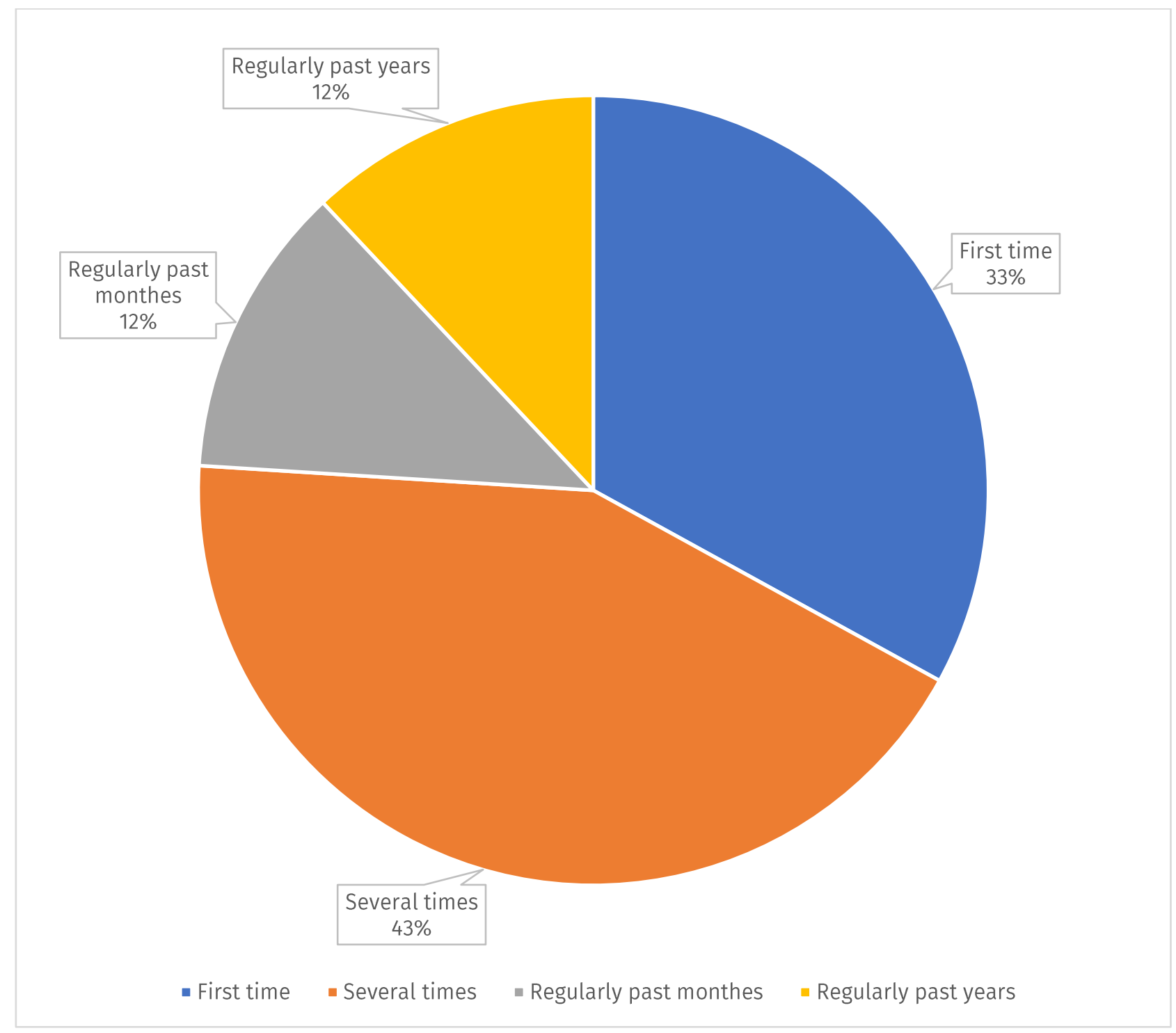

Figure 1. Frequency of visitors of mini hotel in \% (based on the results of the survey)

\section{Empirical Findings and Discussion}

Figure 1 shows the frequency of visits to the hotel. From the data presented it is clear that $77 \%$ of customers turn to mini-hotel services almost regularly. 


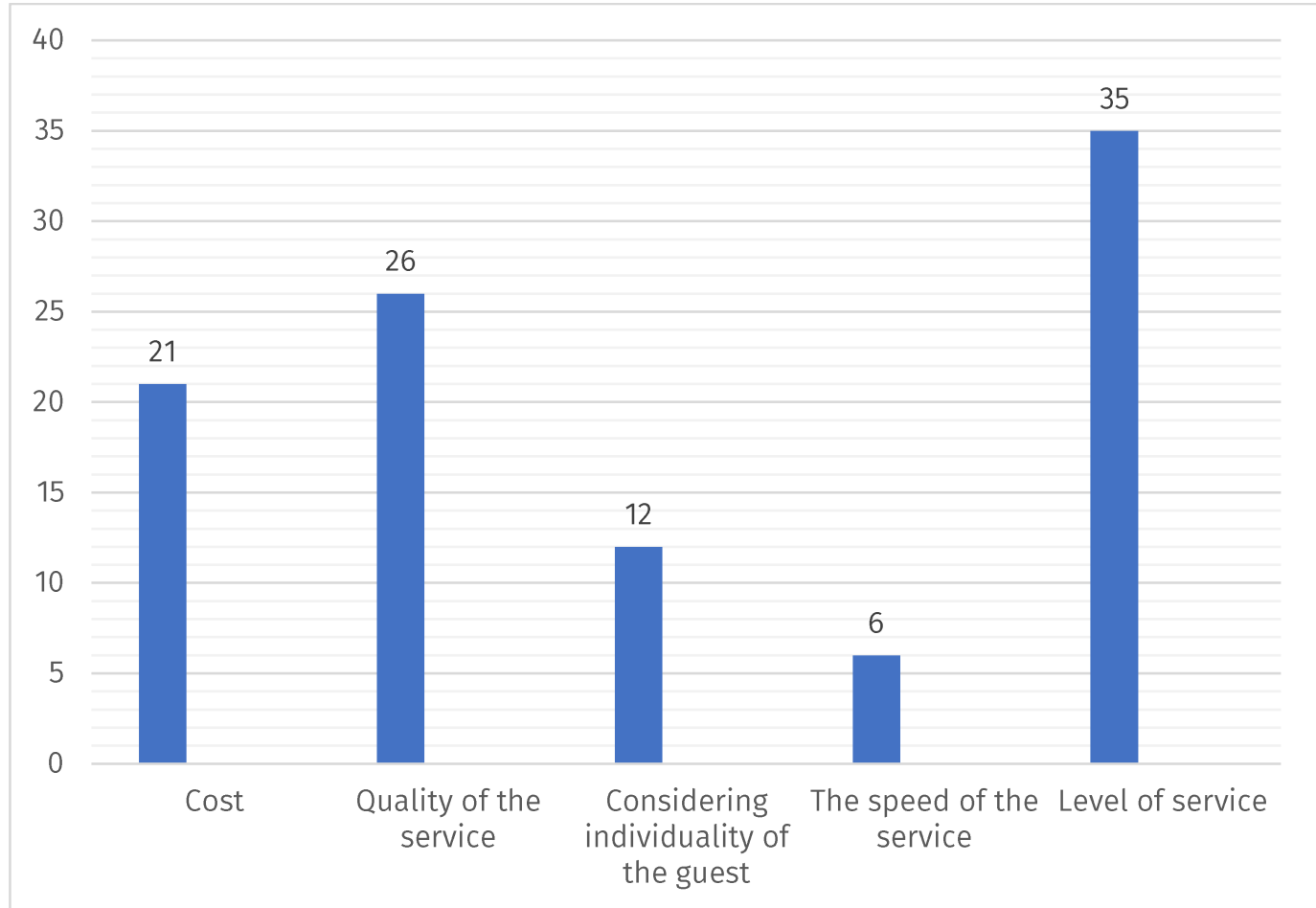

Figure 2. The most significant hotel selection factors, \% (based on the results of the survey)

Figure 2 presents the most significant factors in choosing a hotel: $35 \%$ of respondents the most significant factor of choosing a particular mini-hotel is considered by the level of service, the second and third place in terms of importance is the quality of service (26\%) and then its cost (21\%).

Figure 3 represents the main motives for choosing a hotel. 55\% chose «favorable living conditions» as the main motive, $31 \%$ identified a pricing policy, $14 \%$ - «good recommendations».

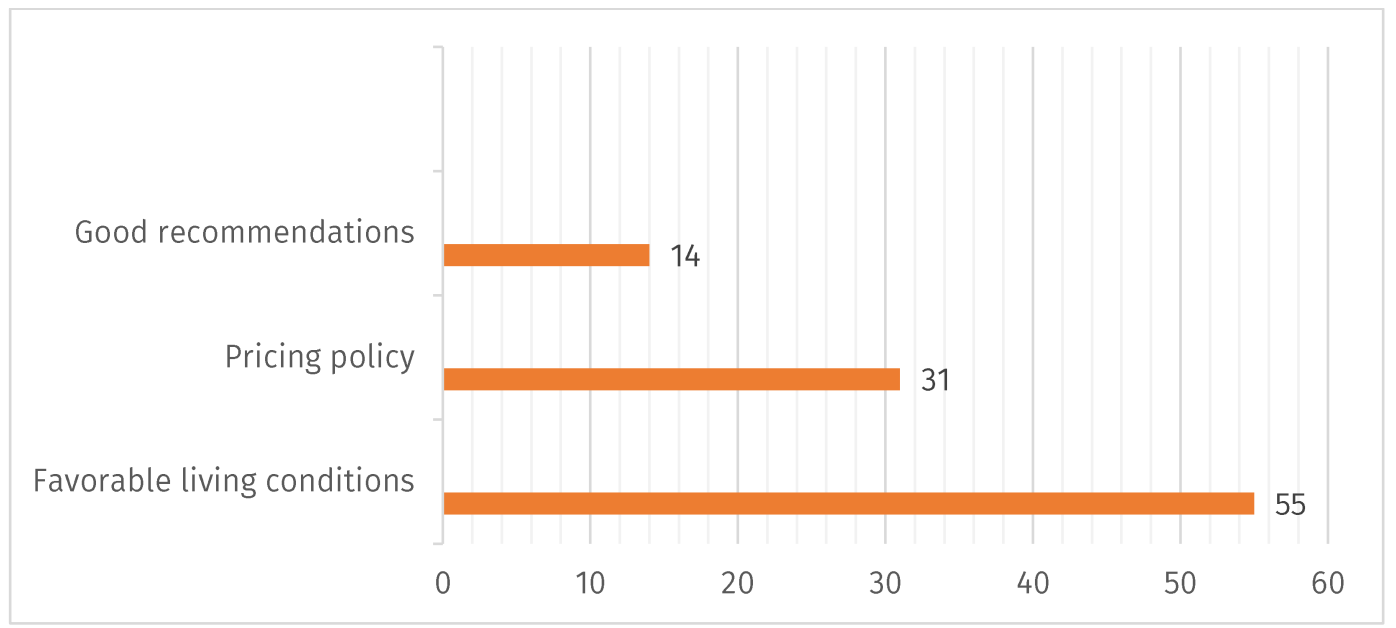

Figure 3 - The main reasons for choosing a hotel, \% (based on the results of the survey) 
According the figure $4,83 \%$ of respondents noted that they are ready to visit a hotel in the future, $2 \%$ will not visit it again, $15 \%$ find it difficult to answer.

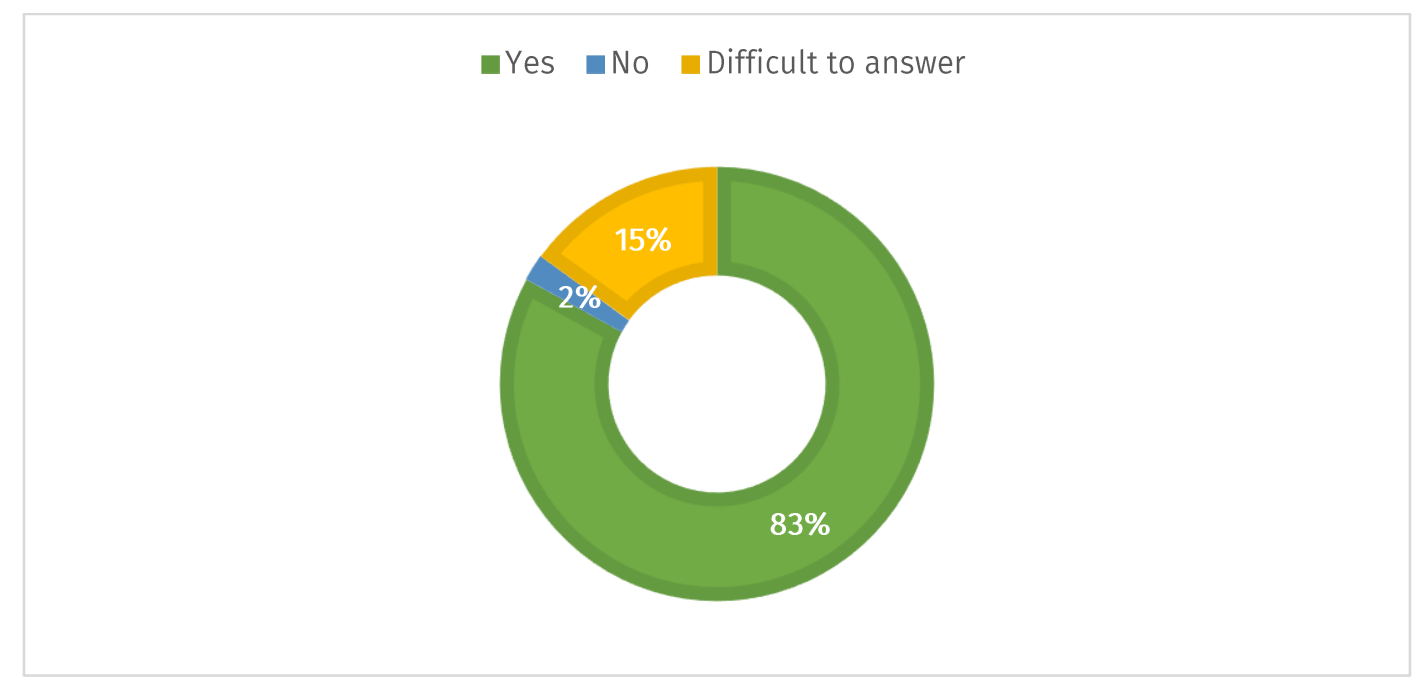

Figure 4. Readiness of customers to visit the hotel in the future, \% (based on the results of the survey).

95\% of customers surveyed said that the psychological climate in the hotel is comfortable. This indicator is a factor of hotel attractiveness. Thus, the study allows us to conclude that the main consumer preferences of customers when choosing a hotel include favorable living conditions, a comfortable psychological climate of hotels, and the level of service. Of great importance is the cost of the service. Note that the development of mini-hotels is impossible without the use of strategic entrepreneurship in the hotel business (Bowie \& Buttle, 2004).

Based on this, mini-hotels in order to build stronger relationships with consumers and best satisfaction of their needs the following tools can be used:

- providing consumers with hotel services additional financial benefits;

- use, along with financial benefits, additional social benefits. This can be achieved through marketing research and the personification of hotel services provided;

- for guests who often use the services of the hotel, the provision of any additional service that not available to other customers, e.g. opportunity to dine in the restaurant for free inns while free breakfasts are provided to the rest of customers (Carlbäck, 2015).

\section{Conclusions}

The formation of guest loyalty as a factor in the sustainable development of small hotels. Hotel industry at the present stage of economic development is an industry with a high 
level of competition, which leads to the search new forms of organizing the hotel business, one of which is mini hotels.

They are created with the aim of fully satisfying the needs of customers, which are increasing every year. Survey data indicate that there is need customers in the services of mini-hotels. A correct understanding of consumer behavior and their value systems will allow the development of new forms of mini-hotels. To achieve this goal, it is necessary to conduct market research on the needs of hotel customers; identify services most in demand; create a system of relationships with hotel service consumers. On the formation of a positive carrying consumers to hotel services also affects the quality of hotel services. Quality of service is a broad and volatile concept. To assess the level of quality provided hotel services, it is necessary to identify indicators and evaluation criteria (Zaltman \& Coulter, 1995). Therefore, in my opinion, in the formation of consumer preferences customers, and therefore loyalty, hotels should pay attention to improving the quality of hotel services.

A survey of hotel services led to the conclusion that the main consumer preferences of customers when choosing a hotel include: favorable living conditions, comfortable psychological climate of hotels, level of service (Berezan, et al., 2013). Mini-hotels are more flexible in providing services and using discount systems than large hotels with a similar level of services. Note that the successful development of mini-hotels is impossible without building relationships with customers (Xu \& Gursoy, 2015). Therefore, a distinctive feature and competitive advantage of mini-hotels is the individualization of service (Kleindorfer, Singhal \& VanWassenhove, 2005).

\section{References}

Berezan O., Raab C., Yoo M. and Love C. (2013). Sustainable hotel practices and nationality: The impact on guest satisfaction and guest intention to return. International Journal of Hospitality Management. DOl.org/10.1016/j.ijhm.2013.03.010

Bitter N.v. (2014). Organizing management system of companies' and clients' relationships. International Journal of Hospitality Management. 34(1):227-233.

Bowie D. and Buttle F. (2004). Hospitality marketing. Oxford: Butterworth-Heinemann. 
Carlbäck M. (2015). Strategic entrepreneurship in the hotel industry: the role of chain affiliation. Journal of Hospitality \& Tourism Research. 35(1), 3-23.

Chudnovskij A.D. (2011). Guidelines for the forming consumer motivations in tourists. Hospitality Research Journal. 20(3), 1-16.

Chudnovskij A.D. and Palshkov A.D. (2012). Modern consumers' requirements for the organization of business meetings and events. Hospitality Research Journal. 23(2), 198-200.

Donskova L.I. and Dunec A.N. (2008). Modern approaches to the assessing the quality of service activity: practical experience (by the example of research of hotel activities). 4(13),197-205.

Duhovnaja L.L., Kobeleva O.V., Shpagina I.V. Small hotels: Problems and development prospects. Retrieved from http://www.naukaru.ru/journal/article/view/19729

Glotova M.A. Small hotel as a growing segment in the structure of accommodation facilities, St. Petersburg, 2015. p. 125-129.

Kleindorfer P.R., Singhal K., VanWassenhove L.N., Sustainable operations management, 2005, p. 482-492.

Kosheleva A.I. (2012). Features of consumer behavior in the hospitality and tourism market. Moscow, Academia.

Kovaleva N.I. and Nikol'skaja E.Yu. (2015). Improving the hotel services quality at enterprises of hospitality industry. Sankt-Petersburg, Peter.

Kovaleva N.I. and Nikol'skaja E.Yu. (2016). Management of customers' behavior of hotel. Sankt-Petersburg, Peter.

Law of the Republic of Kazakhstan on Tourist Services. Retrieved from https://online.zakon.kz/Document/?doc_id=31566262\#pos=1;-110

Levykin V.M. and Djevon V.V. (2014). Developing a mathematical model of the timing of the project mini-hotels, improving its competitiveness. Tourism Management. 32, 310320.

Levykin V.M. and Djevon V.V. (2014). Studing customer satisfaction and loyalty in the minihotel project. Tourism Management. 33, 270-276.

Nikol'skaja E.Ju. and Vahrina Yu.V. (2015). Increasing hotel customer. Moscow, Academia. 
Shahovalov N.N. (2007). Internet Technology in Tourism. Retrieved from http://www.naukaru.ru/journal/article/view/17394

Xu X. and Gursoy D. (2015). Influence of sustainable hospitality supply chain management on customers' attitudes and behaviors. Annals of Tourism Research. 37(2), 397-422.

Zaltman, G. and Coulter R.H. (1995). Seeing the voice of the customer: Metaphor-based advertising research. Journal of Travel Research. 45, 140-149. 